\title{
Towards an innovative model of complementary opposites analysis in the field of sciences and humanities
}

\author{
[Hacia un modelo innovador de analisis de opuestos complementarios en \\ el campo de las ciencias y las humanidades]
}

\author{
Humberto Ortega-Villasenor
}

DOI: 10.18355/XL.2019.12.03.12

\begin{abstract}
These are dark days in Europe, in both developed and developing countries in the Western world. Our human condition and our survival as a species are endangered, under attack from multiples fronts (economic, political, social, moral, among others). The neo-liberalism and free trade of the last 40 years have proven to be less than effective in achieving the type of development that brings benefits, equity and sustainability to the populations that live in the region. Far from it, this development model has fostered social injustice, an unprecedented polarization of processes, growing concentrations of wealth, political and financial power in the hands of the very few, and above all, a monopolistic power wielded by a tiny elite over a wide range of activities that affect the fate of millions of human beings. We believe that a review of the ideas that connect thinkers like Søren Kierkegaard and Karl Marx can serve to build a complex critical scaffolding for understanding the orientation of these developments and estimating their historical weight and transcendence. In fact, we contend that in an extensive and profound sense, the critique that Kierkegaard made of his times (1846) with regard to the bourgeois Christian world comes ironically close to the Marxist critique of the bourgeois capitalist world (1847). This represents a relevant convergence that can shed light on the future consequences of current developments and help to find feasible solutions for preventing or counteracting their negative impact on the majority over the medium and long terms.
\end{abstract}

Key words: Christianity, historical materialism, neoliberalism, neo-totalitarianism

\section{Resumen}

Hoy en día se viven momentos difíciles en Europa, en países desarrollados y en vías de desarrollo del llamado mundo occidental. Nuestra condición humana y supervivencia como especie están en peligro. Son objeto de agresiones múltiples desde varios frentes (económicas, políticas, sociales, morales, entre otras). El neoliberalismo y el libre comercio de los últimos 40 años, no han resultado del todo eficaces en lograr un tipo de desarrollo que resulte equitativo y sustentable para las poblaciones que habitan en la región. Muy por el contrario, han promovido la injusticia social, una inaudita polarización de procesos, la concentración acelerada de la riqueza, el poder político, el financiero y, sobre todo, el poder monopólico que ejerce una minúscula élite sobre un amplio espectro de actividades que afectan el destino de millones de personas. Creemos que, a partir de la revisión de las ideas que ligan a pensadores como Soren Kierkegaard y Karl Marx, es posible construir un andamiaje crítico complejo que nos ayude a entender la tendencia de esos cambios, estimar su peso histórico y caracterizar sus ramificaciones neo-totalitarias para el siglo XXI. De hecho, la crítica que Kierkegaard hace a su época (1846) en torno al mundo burgués-cristiano se acerca con ironía a la crítica marxista del mundo burguéscapitalista (1847); lo cual, resulta una convergencia notable para tratar de anticipar integralmente los desenlaces a futuro de esos fenómenos y encontrar soluciones 
viables que permitan prevenir o contrarrestar su impacto negativo para la mayoría en el mediano y largo plazos.

Palabras clave: cristianismo, materialismo histórico, neoliberalismo, neo-

totalitarismo

\section{Introducción y contexto}

Si queremos sanar nuestro mundo inestable y fracturado, necesitamos cambiar el rumbo y hacerlo ya.

Jason Hickel, Goldsmiths, Universidad de Londres, (OXFAM Briefing Paper, 2018: 8)

Si uno se pone a reflexionar, hace cuarenta o cincuenta años nos habría parecido altamente improbable que las formas del marxismo y del cristianismo hubiesen hallado un terraplén común en Europa debido al deterioro político del marxismo y la propia marginación social del cristianismo en esa región del mundo (David Lyle Jeffrey, 2011: 967). En fechas más recientes, sin embargo, un cierto tipo de crítica marxista de las instituciones ha encontrado aliados entre los liberales tradicionales y los cristianos de la cultura intelectual más radicalmente ortodoxa (desde el punto de vista bíblico) especialmente en Gran Bretaña, Canadá y Estados Unidos (Jeffrey, 2011: 967-968). ¿A qué se debe? Quizás, a los escandalosos excesos en los ingresos que percibe un reducidísimo número de personas en comparación con los colectados por miles de millones de seres humanos. Una diferencia que se incrementa día con día, como lo reporta el dramático informe publicado por OXFAM en enero de 2018:

"El año pasado se produjo el mayor aumento de la historia en el número de personas cuyas fortunas superan los mil millones de dólares, con un nuevo milmillonario cada dos días. En 12 meses, la riqueza de esta élite ha aumentado en 762000 millones de dólares. Este incremento podría haber terminado con la pobreza extrema en el mundo hasta siete veces. El $82 \%$ de la riqueza generada durante el último año fue a parar a manos del $1 \%$ más rico, mientras que la riqueza del $50 \%$ más pobre no aumentó lo más mínimo. La riqueza extrema de unos pocos se erige sobre el trabajo peligroso y mal remunerado de una mayoría" (S/A, "Premiar el trabajo, no la riqueza", Informe de OXFAM, enero de 2018:.2).

Esta disparidad extrema, trae aparejada necesariamente una deshumanización sin precedentes que avanza a gran velocidad y que abraza un enorme mosaico de actividades. Por esa razón, se justifica discernir sobre el significado de este tema, y lo que consideramos representa una crítica marxista y cristiana emergente, que puede resultar muy valiosa. Lo hacemos, con un enfoque cultural un tanto excéntrico como puede ser el mesoamericano y desde la perspectiva del campo periférico con el que estoy familiarizado, que es el de la interdisciplinariedad. Se recurre a disciplinas humanísticas que no se constriñen al campo de la Teología y la Filosofía, precisamente para dar cabida a otros campos del saber.

Creo que Kierkegaard y Marx comparten una postura equidistante aunque opuesta frente a la dialéctica hegeliana. Por un lado, Marx invierte la estructura dialéctica de Hegel para explicar y resolver las etapas de su materialismo histórico, en tanto que Kierkegaard construye la crítica del mundo cristiano de su época (mitad del siglo XIX), a partir de una convicción religiosa superior y opuesta a la estética y a la ética como rectora de la vida interior y las decisiones del individuo. En ese sentido, ambos planteamientos resultan para nosotros complementarios y paradójicamente

XLinguae, Volume 12, Issue 3, June 2019, ISSN 1337-8384, eISSN 2453-711X 
convergentes por su fecundidad en identificar no sólo los errores, exageraciones y desaciertos ocurridos en el siglo XX, por cuanto a emergencia de totalitarismos políticos (como el nazismo, fascismo, comunismo soviético, etc.), sino por las múltiples guerras ocurridas y las dos conflagraciones mundiales que tuvieron lugar en esa centuria.

Sirven también para poder analizar lo que constituye el eje nodal de nuestras preocupaciones en torno a este tema en el siglo XXI y que, entiendo motivan el reunimos con cierta urgencia en esta ocasión. Es inaplazable enfrentar los signos de la decadencia de Occidente, en especial de Estados Unidos, Europa y sus respectivas zonas de influencia en otros continentes, ante los azares que plantea el proyecto de su minúscula plutocracia en su tentativa por señalar el rumbo y dirigir los destinos de la Humanidad en su conjunto. Ese será el propósito de este breve trabajo.

\section{Antecedentes y marco teórico}

Como dijo Louis Brandeis, juez de la Corte Suprema de los Estados Unidos, "en este país, podremos tener democracia o podremos tener una enorme riqueza concentrada en las manos de unos pocos, pero no podremos tener ambas cosas a la vez."

Louis D. Brandeis Legacy Fund for Social Justice, (En: https://www.brandeis.edu/legacyfund/bio.htm)

Antes que otra cosa, es preciso fincar bien el binomio Marx y Kierkegaard desde el punto de vista conceptual. Para ello, vale la pena traer a colación un artículo titulado "El nihilismo europeo" (1940), publicado en español en El hombre en el centro de la historia. Ahí, Karl Löwith (célebre alumno alemán de Edmund Husserl y discípulo de Martin Heidegger), reflexiona sobre Kierkegaard y Marx en la misma línea que lo hizo en su clásico De Hegel a Nietzsche, a saber:

"Entre los discípulos de Hegel fueron Marx y Kierkegaard quienes comprendieron de la forma más radical el fin inherente a la filosofía hegeliana. Ambos se plantearon, pues, la pregunta de cómo superarlo. Su respuesta fue: un nuevo comienzo sólo puede conseguirse por medio de una ruptura decidida con Hegel, y no mediante la continuación del camino que éste ya recorrió hasta el final [...] Cuando ambos reconocieron que la mediación hegeliana de la razón con la realidad carecía precisamente de realidad, opusieron la decisión a dicha mediación; Marx lo hizo tomando partido por un mundo terrenal nuevo y Kierkegaard, por el viejo Dios cristiano, al tiempo que ambos disolvían el orden establecido, aunque fuera yendo en direcciones contrarias" (Patricia C. Dip, 2011: 2-3).

Por esa razón, Karl Lowith los concibe como pensadores consecuentes con el objeto de describir la crítica al mundo burgués en su forma capitalista (Marx) y cristiana (Kierkegaard). Sin embargo, no todos están de acuerdo. Por ejemplo, para Patricia Dip, Kierkegaard y Marx "no representan un quiebre revolucionario con la filosofía del siglo XIX como lo plantea Lowith" (2011: 3). Esta investigadora aduce varias razones,

"Si bien estos pensadores pueden ser concebidos "conjuntamente" como filósofos que permiten describir la época de la "alienación" a la que conduce el desencantamiento del mundo burgués, mientras la crítica de Marx es "sociológica" y pretende producir efectos emancipatorios, el interés de Kierkegaard es "psicológico" y se centra en una 
crítica que no conduce a la búsqueda de la emancipación política sino más bien a la afirmación de la conciencia moral de la burguesía” (Dip, 2011:3).

Sin embargo, los matices que introduce Dip en su argumentación introducen elementos teóricos substanciales que vienen a configurar un andamiaje capaz de afrontar de manera interdisciplinaria la complejidad del problema y caracterizar con mayor rigor su especificidad en el siglo XXI, sobre todo teniendo en la mira la idea de encontrar soluciones que resulten viables hacia el futuro. (según Dip, 2011: 3-4),

"Si bien la complementariedad puede hallarse en el punto de partida, a saber: la decisión de oponerse a la presunta identidad de pensamiento y realidad defendida por Hegel, ya en el momento de realizar un diagnóstico de la crisis epocal, que el joven Marx describe en términos de alienación y Kierkegaard en términos de "desesperación", disienten. Este disentimiento en el diagnóstico de la crisis trae consecuencias en lo que respecta a la solución a la misma [...], que tampoco comparten más que en lo que respecta al punto de partida, a saber: el enfrentamiento con Hegel, mediado, en su origen, por Schelling.” (Dip, 2011: 5).

No obstante, estamos convencidos que las diferencias subrayadas por Dip, facilitan el abordaje del fenómeno desde distintas perspectivas (política, económica, social, moral), colocando en el centro del problema la crisis de desigualdad que priva hoy en el mundo occidental. En ese sentido, creo que hay puntos de convergencia fundamentales en el pensamiento de Kierkegaard y de Marx que avalan una concurrencia provechosa para nosotros. Como lo ha expresado Rosa Pavanelli,

"Las personas trabajadoras saben desde hace años que la mayor parte de los beneficios de la globalización está reservada a una pequeña élite que se considera a sí misma intocable. Los mitos del modelo de globalización actual se están desmoronando como si fuera un castillo de naipes, y con ellos cae también la credibilidad de sus defensores y la confianza en las instituciones. La evasión y la elusión fiscal sin tapujos, las privatizaciones, los recortes en los servicios y décadas con los salarios congelados no son producto del azar. Es necesario tomar medidas urgentes y radicales para invertir en servicios públicos universales, generar trabajo decente y redistribuir la riqueza" (S/A, "Premiar el trabajo, no la riqueza", Informe de OXFAM, enero de 2018: 8).

\section{Materialismo histórico y disyuntiva moral}

"Nuestros líderes son conscientes de ello, pero en lugar de adoptar medidas para reducir la concentración de la riqueza y la desigualdad, están más interesados en restringir la democracia y la libertad de expresión para demandar una sociedad más justa”.

Louis D. Brandeis Legacy Fund for Social Justice, (En: https://www.brandeis.edu/legacyfund/bio.htm)

Como bien sabemos, el neoliberalismo y el libre comercio en Occidente no han sido del todo exitosos en los últimos 40 años. Ambos han favorecido un tipo de desarrollo económico desigual entre espacios geográficos, países, y al interior de los países, beneficiando a una élite cada vez más delgada. Algunas zonas crecen más rápido en detrimento de otras que no crecen en proporción ni al mismo tiempo. Como expresa Guy Ryder, 
"La mayoría de las personas quiere vivir en sociedades mucho más equitativas. Como reflejo de este deseo, la reducción de la desigualdad se ha convertido en uno de los temas prioritarios en la agenda de las instituciones internacionales y de los líderes políticos. Muestra de ello son los Objetivos de Desarrollo Sustentable de las Naciones Unidas, donde el objetivo 10 establece "reducir la desigualdad en y entre los países", y el objetivo 8 hace un llamamiento a fomentar un crecimiento económico inclusivo, a alcanzar el pleno empleo y a lograr trabajos decentes para todas las personas." (S/A, "Premiar el trabajo, no la riqueza" (Informe de OXFAM, enero de 2018:.7).

Como alguna vez observara con sutileza el filósofo Luis Recaséns Siches, lo capital en Marx es su aspiración socialista; en realidad, la teoría económica de la Historia es una curiosa peripecia accidental. Seguramente el afán vital insobornable, animador de toda su existencia -y también de su obra teórica, de manera consciente o más bien subconsciente- fue en Marx una transformación social al servicio de la justicia distributiva, en un sentido colectivista. Más en su época, la principal crítica que se dirigía contra el socialismo era la de que constituía una utopía, un bello sueño irrealizable. Marx quiso fraguar para el socialismo una base muy firme que resistiera sobre todo a esa acusación de ser un ideal de imposible realización: y por eso hizo menos hincapié en un programa de deber ser y tuvo la peregrina ocurrencia de presentarlo como una forzosidad independiente de los designios voluntarios de los hombres, es decir, como un tener que ser, apoyado por una necesidad inexorable, que habría de presentarse en el próximo estadio de la evolución económica (Véase, Recaséns, 1965: 452).

Sin embargo, la vitalidad del pensamiento de Marx en el mundo de hoy es de llamar la atención. En los últimos años, se han producido fusiones de importantes compañías privadas y se ha fortalecido la tendencia a la monopolización de las empresas multinacionales en una proporción desmedida (ello en menoscabo de las pequeñas y medianas empresas). Asimismo, se ha expandido la monopolización de los mercados, dando lugar a demasías inaceptables en la concentración del capital. Al grado tal que, en pleno siglo XXI, unas cuantas personas y familias atenazan los escenarios políticos, económicos y culturales de Occidente de una manera intimidante, aunque distinta a las formas totalitarias y transpersonalistas del absolutismo, las dictaduras y el estatismo de siglos anteriores (en particular, de los siglos XIX y XX). Valga mencionar como paradoja, que Rusia, China y algunos países asiáticos y escandinavos presentan hoy modalidades y escalas varias que escapan a dicho cartabón.

Recordemos que "son expresiones del transpersonalismo las doctrinas de la Antigüedad pagana, las romántico-tradicionalistas, los idearios ultraconservadores, el militarismo, el belicismo, el fascismo, el nazismo, el comunismo soviético y otros programas y realidades similares" (Recaséns, 1965: 502). En este momento, estamos en presencia de una forma de transpersonalismo o totalitarismo muy nueva, de apariencia joven, democrática y global. Sin embargo, al igual que las anteriores, el ser humano "no es considerado como ser moral con dignidad, como persona que tiene una singular misión a cumplir por propia cuenta; por el contrario, es utilizado tan sólo como mero instrumento o material para la realización de finalidades que trascienden su propia existencia. Un artefacto que se maneja como instrumento para fines ajenos a su vida; por lo tanto, se le valúa no como un sujeto que es sustrato de la tarea moral, sino únicamente como mercancía que tiene un precio, en la medida en que resulta aprovechable para una obra transhumana (ajena a la individualidad) (Véase, Recaséns, 1965: 502).

El Informe de OXFAM, enero de 2018 señala lo siguiente, 
"Los monopolios generan beneficios excesivos para sus propietarios y accionistas a expensas del resto de la economía. La capacidad que tienen los monopolios para generar riqueza extrema queda demostrada en el caso de Carlos Slim, el sexto hombre más rico del mundo. Su fortuna proviene del monopolio casi absoluto que ha sido capaz de ejercer sobre los servicios de comunicaciones (líneas de teléfono fijas, móviles y de banda ancha) en México. La OCDE ha señalado que este monopolio tiene efectos muy negativos sobre los consumidores y la economía en su conjunto" (2018: 12).

Por otra parte, el pensamiento crítico de Kierkegaard a este respecto resulta también asombroso (y me refiero sobre todo a sus trabajos posteriores a Postcript). Kierkegaard buscó rescatar al individuo de la veneración que profesaba por la idea de modernización a ultranza nutrida por un modo de subjetividad egoísta impulsado por la iglesia danesa de su tiempo. "La cristiandad es como la edad en que el hombre decidió construir el Reino de Dios en la tierra. Kierkegaard vio a la cristiandad como una religión cultural, como un mesianismo profano, en el cual el hombre mismo estaba programado para ser el Mesías, en una era que adoraba a los nuevos dioses, el progreso, la ciencia, la educación y la humanidad. Cosas que nos dieron el Siglo de Progreso, un siglo de progresiva preocupación por la criatura en lugar del Creador". (Howard A. Johnson citado por Owen C. Thomas, 2012: 74). Habrá en este caso que preguntarnos si no es una situación parecida a la que vivimos todos en Occidente. Claro que el cuestionamiento moral también va dirigido a las élites, sobre todo cuando uno pondera su responsabilidad en el ámbito económico,

"El poder del monopolio se agrava por el clientelismo, por la capacidad de los intereses privados de manipular las políticas públicas para reforzar los monopolios existentes y crear otros nuevos. Acuerdos de privatización, entrega de recursos naturales por valores irrisorios, corrupción en las compras públicas, exenciones y bonificaciones fiscales, así como vacíos legales en la regulación fiscal son distintas maneras en que los intereses privados de las personas con influencias se enriquecen a expensas de lo público". (Informe de OXFAM, enero de 2018: 13).

Si admitimos que estamos en presencia de un neo-totalitarismo, cabe preguntar, ¿En qué consistirían las diferencias entre el transpersonalismo tradicional y el que sufre Occidente en estos últimos años? Básicamente, en que es impulsado no por un Estado $\mathrm{u}$ organización regional en particular, sino por una élite que concentra el poder político, económico, social, mediático y cultural del mundo occidental en la actualidad.

"Las fortunas de los súper ricos aumentan aún más gracias a la evasión y elusión fiscal (de los propios súper ricos y de las empresas de las que son dueños o accionistas). Tal y como se ha destapado con los escándalos de los Papeles de Panamá y los Papeles del Paraíso, gracias a una red mundial de paraísos fiscales los súper ricos esconden al físco al menos 7,6 billones de dólares. Una nueva investigación elaborada por el economista Gabriel Zucman para este informe indica que esto significa que el 1\% más rico del mundo evade o elude impuestos por valor de 200000 millones de dólares. Los países en desarrollo dejan de recaudar por lo menos 170000 millones en ingresos fiscales de los beneficios de las empresas y de los súper ricos". (Informe de OXFAM, enero de 2018: 11). [...]

"Incluso milmillonarios que han construido su fortuna operando dentro de mercados competitivos, lo han hecho a base de reducir los salarios y las condiciones laborales de la mano de obra, obligando a los países a entrar en una carrera suicida a la baja en

XLinguae, Volume 12, Issue 3, June 2019, ISSN 1337-8384, eISSN 2453-711X 
cuanto a salarios, derechos laborales y beneficios fiscales. Mientras todo esto ocurre, los niños y niñas más pobres del mundo, especialmente, las niñas, están condenadas a vivir toda su vida en la pobreza, ya que las oportunidades sólo llegan a los niños y niñas de las familias ricas" (Informe de OXFAM, enero de 2018: 14).

Los efectos colaterales de esta concentración excesiva del capital y del poder político en Occidente han conducido a la monopolización de procesos variopintos y requerido el diseño e implementación de medidas cada vez más extremas y sofisticadas. Los beneficios económicos están cada vez más concentrados entre quienes más tienen. Mientras millones de trabajadores y trabajadoras en el mundo siguen percibiendo salarios de pobreza, las retribuciones de los accionistas y de los directivos se han disparado (OECD Employment Outlook, 2012),

"En Sudáfrica, la mitad de todos los ingresos salariales va a parar al $10 \%$ más rico, mientras que el $50 \%$ más pobre de los trabajadores y trabajadoras apenas recibe el $12 \%$ de toda la masa salarial. Con poco más de un día de trabajo, un director general en Estados Unidos gana lo mismo que un trabajador durante todo un año. Sistemáticamente, la mayor parte de los empleados mejor remunerados son hombres. En promedio, a un director general de cualquiera de las cinco mayores empresas del sector textil le basta con trabajar cuatro días para ganar lo mismo que una mujer que trabaja en el mismo sector en Bangladesh durante toda su vida. (S/A, "Premiar el trabajo, no la riqueza" (Informe de OXFAM, enero de 2018: 13).

Esto explica el carácter neta y profundamente anticristiano del ideario transpersonalista que pretende no sólo desconocer por entero la dignidad moral del individuo y degradar al hombre a la condición de siervo o esclavo, de puro medio, desconociendo los principios de la civilización cristiana y las normas de la cultura occidental; también al grado de deshumanización al que parecen apuntar masivamente todas sus estrategias y proyectos: por ejemplo, de disminución poblacional, de desindustrialización, de control ideológico y mediático, de degradación moral, etc. Otra peculiaridad sin precedentes quizás sea la de prescindir del andamiaje de los Estados-nación, desestimando el papel de los nacionalismos, los particularismos culturales, la memoria histórica de los pueblos, las estructuras sociales y familiares, así como el diálogo en foros internacionales multilaterales. Muy por el contrario, se ponderan o exaltan las desigualdades cognitivas, las socio-económicas y culturales de los diversos pueblos y etnias. Se busca preservar a toda costa el dominio de los recursos, el control de la ciencia, la tecnología, los medios de información y la conducta de las mayorías a fin de garantizar los privilegios acumulados.

\section{Objetivos y estrategias}

"De hecho, las discontinuidades, inseguridades y volatilidades parecen estar proliferando todo el tiempo y los cambios futuros parecen estar acelerándose hacia nosotros a un ritmo más rápido de lo que podríamos haber esperado".

Christopher John Parry, Almirante de la Royal Navy Británica, (Preámbulo del DCDC Strategic Programme, 2007-2036: iv).

A continuación nos proponemos analizar brevemente cuatro de los vectores apenas esbozados en el párrafo anterior, mismos que definen o caracterizan ese neototalitarismo en el siglo XXI. Lo haremos con base en un estudio muy completo de tendencias estratégicas elaborado por el Centro de Desarrollo de Conceptos y Doctrina del Ministerio de Defensa del Reino Unido. Se trata de un documento que, 
no obstante ser base de la política de defensa de ese país, resulta pertinente considerar como fuente informativa confiable, pues con un tratamiento prospectivo interdisciplinario, toma en cuenta variables cruciales que muchas veces son ignoradas o pasadas por alto en diagnósticos académicos y estudios prospectivos serios. Por vía de contraste, se intercalan algunas citas extraídas del último informe de OXFAM, enero de 2018, así como del publicado por esa misma ONG en el año 2014.

\subsection{Desindustrialización}

Comenzaremos con las estrategias dirigidas a debilitar los ritmos de crecimiento económico y lograr en el mediano y largo plazos, la destrucción del modelo industrial. Se tiene el claro propósito de lograr el crecimiento cero y debilitar el poder económico y político de los Estados-nación en su conjunto, en especial, de los países periféricos que abastecen de recursos materiales y mano de obra (según William I. Robinson, 2014; Daniel Estulin, 2013). Es probable que la economía mundial siga creciendo al 2-3\% anual hasta al menos 2020, acompañado de mejoras generales en materia de bienestar, con un crecimiento más espectacular en la región de Asia y del Pacífico. Sin embargo, el crecimiento será desigual, variando entre distintas regiones a lo largo del tiempo. Probablemente África Sahariana se quede atrás de otras regiones debido a factores ambientales y desafíos políticos y demográficos vinculados con la corrupción endémica. (según DCDC Strategic Programme, 2007: 7). De no disminuir los ritmos de crecimiento, la competencia por los recursos de todo tipo se intensificará. Las economías desarrolladas y en desarrollo buscarán asociaciones políticas y económicas con los estados para garantizar suministro (según DCDC Strategic Programme, 2007: 6).

Cabe rememorar los procedimientos para inducir esa desindustrialización, primero se constriñe el poder financiero del Estado-nación, para ser exclusivamente garante de las operaciones financieras y equilibrar la balanza de pagos; luego, se limita la capacidad productiva del Estado para utilizar los recursos financieros disponibles e impulsar los cambios que sean necesarios para reactivar la economía, generar empleo y propiciar un desarrollo más justo y equilibrado que beneficie a la población; Posteriormente, se distienden las reglas financieras, se incentiva la especulación, el desvío de recursos hacia los llamados paraísos fiscales en perjuicio del papel tributario del Estado y del cumplimiento de sus obligaciones económico-sociales e históricas ante sus poblaciones. Finalmente, se mina el poder político y la soberanía del Estado al servicio de los intereses y decisiones de la minúscula casta de personas que detenta los principales medios de producción (véase Robinson, 2013).

"Globalización y desregulación son fenómenos que se consideran indisociables. Esto es un error. Se asume que, cuanto más globalizada e integrada esté la economía, mayor ha de ser la desregularización, y que no es posible tener una cosa sin la otra. Países como Corea del Sur, o más recientemente Brasil, han logrado reducir la desigualdad mientras aumentaban su participación en la economía mundial, y lo han hecho, en parte, gracias a una regulación considerable en varios aspectos de sus economías. La integración de los mercados y de la economía puede ser un importante motor del crecimiento y la prosperidad. Pero ambos deben gestionarse cuidadosamente en el interés de toda la población, de manera que los beneficios del crecimiento se distribuyan justamente. Si no se ejerce ningún control, pueden volverse una amenaza para nuestras democracias y un problema para construir sociedades más equitativas. Es necesario definir una nueva visión de la globalización" (Informe de OXFAM, enero de 2018: 64).

XLinguae, Volume 12, Issue 3, June 2019, ISSN 1337-8384, eISSN 2453-711X 
Si uno observa detenidamente, la desregulación per se no ha significado otra cosa, sino la subordinación sistémica de los países periféricos, su dependencia crónica de los países desarrollados, de la inversión del capital foráneo y las grandes trasnacionales. Ha conducido al control de los espacios, los recursos naturales y los procesos productivos por parte de estos, al desmantelamiento acelerado de la planta productiva local, la automatización paulatina de los procesos industriales, la depauperación de grandes segmentos poblacionales, el desempleo crónico, la multiplicación de actividades informales para sobrevivir, etc.

“Actualmente, es difícil encontrar un líder político o un líder empresarial que no exprese públicamente su preocupación por la desigualdad. Sin embargo, lo que cuenta son las acciones, no las palabras, y en esto casi todos los líderes suspenden. De hecho, muchos de ellos promueven activamente políticas que contribuyen al aumento de la desigualdad. [...] Development Finance International han elaborado un índice que analiza las políticas adoptadas por 152 Gobiernos en ámbitos que podrían contribuir a hacer frente a la desigualdad, poniendo de manifiesto que la mayoría de los Gobiernos no hace lo suficiente para cerrar la brecha" (Informe de OXFAM, enero de 2018:.10).

\subsection{Disminución de la población}

Cabe preguntar sobre las amenazas que plantea el crecimiento poblacional para la élite bajo las actuales circunstancias. De acuerdo con el estudio de tendencias estratégicas citado, el crecimiento sostenido de la población, la competencia económica agresiva y el aumento del consumo, junto con la rápida modernización y urbanización, da lugar a una intensiva explotación y presión sobre recursos de todo tipo. Estas tendencias se agravarán dadas las consecuencias del cambio climático y los cambios ambientales. En consecuencia, la disponibilidad y el flujo de energía, alimentos y agua serán problemas críticos, con el potencial de fluctuaciones y desequilibrios tanto en la producción como la distribución a nivel global, regional y local (según DCDC Strategic Programme, 2007: 7).

"El equilibrio entre los miembros económicamente activos e inactivos de la sociedad se alterará significativamente y habrá fuertes diferenciales de edad entre el primer mundo que envejece y el tercer mundo juvenil. En general, la población global envejece y el desempleo cíclico se generalizará, especialmente entre los marginados urbanos en crecimiento, que probablemente constituyan el $25 \%$ de la población mundial. Marcados desequilibrios de edad, entre regiones y países, junto con los desequilibrios de género, acentuarán y exacerbarán las tensiones, tanto a nivel regional como internacional” (DCDC Strategic Programme, 2007: 8).

Se calcula que para 2035 , el $60 \%$ de la población mundial vivirá en áreas urbanas. Habrá un crecimiento sustancial en los barrios de asentamientos urbanos no planificados, lo que aumentará el costo de los recursos y el impacto medioambiental. En algunos casos, el desarrollo rápido e incontrolado desafiará la capacidad de crecimiento (según DCDC Strategic Programme, 2007: 8).

Por esas razones, la disminución de la población se ha convertido en una estrategia prioritaria. Obviamente, se contemplan las estrategias tradicionales, como la propagación de las guerras, las guerras de baja intensidad, los conflictos armados, el apoyo a grupos rebeldes y a movimientos de resistencia, la fabricación y suministro de armas, la desaparición forzada, etc. (según Robinson, 2014: 11). Por otro lado, está el desarrollo, producción y proliferación de armas químicas, biológicas, radiológicas y nucleares; el acceso a la tecnología que permite la producción y distribución de 
productos químicos, biológicos (según Estulin, 2013: 11-19). Es probable que aumenten las armas radiológicas y nucleares (QBRN). De acuerdo con el Estudio sobre tendencias estratégicas,

"Habrá un mayor riesgo de catástrofe humanitaria en la mayoría de las regiones vulnerables, causadas por una mezcla de cambio climático, presiones sobre los recursos, distribución desigual de la riqueza, el efecto de las enfermedades y la incapacidad de las autoridades para hacer frente al crecimiento de la población y a la urbanización. La migración y la urbanización, dentro de los países y entre las regiones, aumentará presión sobre la infraestructura y la gobernanza y posiblemente desestabilice las comunidades" (DCDC Strategic Programme, 2007: 6).

Colateralmente, se promueve el surgimiento de nuevas enfermedades y nuevas plagas; la modificación genética de semillas, el desarrollo de la industria agro-química y los pesticidas. La monopolización de la agricultura, el control de la industria de alimentos $\mathrm{y}$, de la industria farmacéutica es un hecho.

Finalmente, no debe pasarse por alto que en espacios periféricos de alto valor en recursos naturales para el mercado, está el impulso de técnicas para inducir el miedo en las zonas urbanas, el terror en las zonas rurales y la emigración de comunidades en terrenos apetitosos para el capital trasnacional.

\subsection{Debilitamiento y desaparición del Estado-nación}

De acuerdo con el Estudio sobre tendencias estratégicas, no obstante que la ciudadanía y la seguridad física sigan siendo importantes en el corto plazo, se prevé a futuro que la lealtad de las personas hacia el Estado y las instituciones estatales en algunos países tienda a disminuir o se vuelva cada vez más huidiza y condicional. Esto responde a factores de desgaste de los particularismos impulsados, según esto, por la propia globalización. Es por eso que la valoración del estudio resulta en este renglón un tanto ambigua o ideologizada,

- La nacionalidad y la etnicidad en ciertos países continuará influyendo en el comportamiento del ser humano y en las relaciones internacionales.

- Las comunidades de la diáspora y sus redes serán dinámicas, aunque impredecibles los aspectos políticos, demográficos y económicos de la globalización.

- El origen físico y cultural de la persona continuará siendo significativo para la identidad, pero será cada vez más selectivo, en función de su utilidad en el contexto y el interés personal.

- Las comunidades se formarán cada vez más en derredor de intereses comunes, y se disolverán rápidamente cuando dichos intereses ya no resulten relevantes (según DCDC Strategic Programme, 2007: 10).

Por otra parte, el estudio prevé que algunas áreas geográficas ("incluidos Estados fallidos, provincias o ciudades, y otras agrupaciones de población"), no estarán sujetas a gobernanza y al Estado de derecho. Asegura que los Estados débiles, mientras continúen reclamando derechos de soberanía, subsistirán a través del comercio ilícito y las actividades del crimen organizado, mientras que otros serán ineficaces para frenar la inestabilidad y contener los reclamos y consecuencias ante presiones transnacionales. Señala que los riesgos asociados con estos espacios sin gobierno y/o mal gobernados ("incluida la actividad delictiva endémica, el auspicio o base de los terroristas, la actividad irregular y el conflicto"), es probable que aumenten y se 
agreguen a la complejidad y, extensión de las cargas para mantener la integridad del sistema internacional (Véase DCDC Strategic Programme, 2007: 16).

Sin embargo, bajo la óptica del Informe de OXFAM, 2014, lo anterior no tiene sustento y es relativo. El debilitamiento del Estado-nación no es atribuible al desvanecimiento inevitable de la mentalidad e idiosincrasia cultural de los pueblos como resultado del desgaste e incidencia de un contexto como la globalización, sino a la apropiación de los procesos políticos y democráticos por parte de las élites económicas (véase Estulin, 2016), que buscan un impacto totalizador y transpersonal en beneficio de unos cuantos. Como dice el estudio, estos procesos tienen efectos notables que afectan por igual a países ricos y pobres:

"El presente informe ofrece ejemplos relacionados con la desregulación financiera, la inequidad de los sistemas fiscales, las leyes que facilitan la evasión fiscal, las políticas económicas de austeridad, políticas que perjudican desproporcionadamente a las mujeres y la apropiación de los ingresos derivados del petróleo y la minería. Cada uno de los breves estudios de caso incluidos en el informe pretende dar una idea sobre cómo este secuestro democrático genera una riqueza ilícita que perpetúa la desigualdad económica." (S/A, "Premiar el trabajo, no la riqueza", Informe de OXFAM, enero de 2014: 3).

Por ende, se avizora el debilitamiento del Estado-nación con miras a su desaparición; sobre todo de aquellos Estados que siendo soberanos, resultan ser autosuficientes en lo alimentario, ejercen todavía control de buena parte de sus recursos estratégicos y buscan el progreso y la equidad para su población. Véanse como ejemplos países como Irán, Iraq, Siria, Líbano en el oriente medio, Egipto y Libia en África, o Venezuela en Latinoamérica, etc.

Desde el punto de vista político, en esos espacios, las élites (exógenas y/o endógenas) discretamente incentivan el caos, el despojo, la guerra civil, la violencia, el terrorismo, las emigraciones. Y, en el renglón económico, como vimos antes, el crecimiento cero, la depauperación, el hambre, la desesperación, el desplazamiento poblacional interno hacia ámbitos y regiones económicamente irrelevantes, etc. En el ámbito cultural, apuntalan el desarrollo de comunidades cosmopolitas alejadas de la Historia y costumbres de los países de origen, propiciando la manipulación de las ideas y costumbres nacionalistas.

Es por esto que, en este rubro, el propio Estudio sobre tendencias estratégicas barrunte de manera velada o simulada sus previsiones como sigue,

- Las presiones transnacionales, la competencia y la globalización pondrán a prueba la robustez y capacidad de recuperación de la gobernanza y los mecanismos sociales en todos los niveles.

- Se requerirán nuevas instituciones de colaboración, filosofías y mecanismos para hacer frente a problemas globales y regionales complejos e interconectados.

- El ejercicio de la soberanía nacional se expresará cada vez más en apoyo de una acción colectiva internacional, pero los regímenes y las políticas seguirán actuando para proteger a sus ciudadanos y mantener sus intereses vitales y estabilidad.

- La responsabilidad de los arreglos internacionales recaerá en los partidos nacionales. Es poco probable el surgimiento de un nuevo poder soberano supranacional (véase DCDC Strategic Programme, 2007: 14).

\subsection{Des-racionalización, técnicas de control psíquico y cambio de valores culturales}


Otra de las líneas estratégicas que modela y caracteriza al transpersonalismo de las élites contemporáneas para reforzar el status quo totalitario e imponer sus enfoques e intereses es la de amplificar o expandir la monopolización del conocimiento, la ciencia y la tecnología con miras a definir sus prioridades y su rumbo. Esto con el fin de fortalecer su postura a largo plazo en términos de concentración del poder, la riqueza y el control social (según Robinson 2013: 8-22).

Se privilegia, por supuesto, el desarrollo selectivo de campos de conocimiento que promuevan directa o indirectamente el evolucionismo, la inteligencia artificial, la nanotecnología, la robótica, el automatismo, etc. El control ideológico y psicosocial de la población se refuerza mediante la educación, el adoctrinamiento y la degradación paulatina de valores humanos. Esto a través de técnicas conductuales y tecnologías de acceso a la información.

"Por una parte, se prevé que la penetración de las TIC permita que más personas accedan y exploten sistemas de información cada vez más interconectados y sofisticados. Por ejemplo, se estima que el $20 \%$ de la población africana se suscribió a teléfonos móviles habilitados para Internet en el año 2010. El Internet y las tecnologías asociadas, junto con las comunicaciones portátiles digitalizadas, se han convertido cada vez más en el medio por el cual se distribuye una mayor gama visual, auditiva y escrita de información en rápida expansión, así como productos de entretenimiento" (DCDC Strategic Programme, 2007: 11).

Aunque los progreses de las TIC y los sistemas avanzados de tránsito masivo puedan aumentar la conectividad entre diásporas étnicas o nacionales y sus comunidades de origen, tenderán a reducir alicientes para una genuina integración y asimilación cultural de pueblos y comunidades, al permitir la existencia de comunidades "virtuales" autónomas a través de los continentes. Comunidades, estas últimas, que no siempre estarán en sintonía con el interés y las aspiraciones de los países y culturas de origen, propiciando la homogeneización y uniformidad de la conciencia, el pensamiento y las ideas.

Se presume que el volumen de información disputará los procesos de apoyo a la decisión que estén basados en la gestión del conocimiento 'ordenado' y organizaciones jerárquicas rígidas. Los procesos de vigilancia tecnológica y las agencias de inteligencia se enfrentarán a la velocidad y la diversidad de las innovaciones, que es probable que "aparezcan" con mayor frecuencia. La tasa de innovación tecnológica reducirá el tiempo disponible para la asimilación y control de la 'cultura' propia, lo que aumenta la probabilidad de resultados que las élites no deseen, pues éstas buscan contar con mecanismos eficaces de control social y prevenir así, la transmisión internacional de riesgos sociales, que incluye: violencia intercomunal, terrorismo y delincuencia transnacional, especialmente el tráfico y el comercio ilícitos (véase Estulin, 2016: 245-249).

Es de suponer que la innovación, la investigación y el desarrollo científico y tecnológico se originen de fuentes internacionales distintas a las tradicionales (países desarrollados) y, por lo tanto, que la regulación y control de nuevas tecnologías resulte más difícil para las élites. En esos casos, la explotación de las fuentes puede conllevar resultados catastróficos para ellas, especialmente las asociadas con nanotecnología, biotecnología y sistemas de armas. Se puede tratar de algo involuntario, por ejemplo, la nanotecnología o la biotecnología fuera de control, o destinada al desarrollo y uso de energía dirigida o a armas de pulso electromagnético (según DCDC Strategic Programme, 2007: 16).

XLinguae, Volume 12, Issue 3, June 2019, ISSN 1337-8384, eISSN 2453-711X 
Por cuanto al cambio de valores, el Estudio espera que el secularismo y el materialismo crezcan en importancia en un mundo cada vez más competitivo e interconectado, sobre todo en países en vías de desarrollo, dado que esas tendencias a la despersonalización y deshumanización se encuentran ya bien enraizadas en las regiones más desarrolladas (según Martina Pavlikova, 2018: 59-60).. Mientras tanto, la mezcla cultural, el ritmo del cambio y una rápida confluencia de ideas modernas y tradicionales se prevé al mediano plazo, en tanto que aumente la tendencia hacia el relativismo moral y hacia valores cada vez más pragmáticos.

Sin embargo, el DCDC Strategic Programme vaticina que esta mutación axiológica no será pareja pues generará respuestas variopintas, sobre todo entre minorías y comunidades tradicionalmente definidas, las cuales buscarán refugio en sistemas de creencias más ortodoxos e ideologías políticas diferentes (2007: 12).

Un último cambio de valores se está alistando, el de la familia. El estudio antes referido apunta que los arreglos familiares se volverán económica y socialmente más diversos y fluidos, moldeados por la cultura, el interés y las circunstancias caracterizados por una combinación de relaciones biológicas funcionales. Sin embargo, es probable que las estructuras tradicionales persistan y es probable que el matrimonio formal siga siendo popular, aunque su carácter y resistencia estén determinados por condiciones económicas y los valores culturales en boga o prevalecientes.

\section{Conclusiones}

"124 millones de personas en 51 países necesitan ayuda urgente para no morir, alertó un informe elaborado por la Organización de las Naciones Unidas para la Alimentación y la Agricultura (FAO), la Unión Europea (UE) y otros organismos internacionales".

$$
\begin{array}{r}
\text { Nota anónima de Afp } \\
\text { (publicada en el Periódico La Jornada, } \\
\text { Viernes 23 de marzo de 2018, p. 36) }
\end{array}
$$

El esfuerzo por convocar a dos pensadores tan disímbolos como Karl Marx y Soren Kiekergaard ha sido provechoso. El potencial de utilizar su relación y diferencia sí que parece grande, y nos mueve a pensar que no termina en este texto, ya que desde una visión de conjunto, ha sido posible urdir y sistematizar un modelo de articulación teórica, epistemológica y filosófica que, por lo visto, permite engarzar, comparar y recuperar aportaciones medulares discordantes y de posturas aparentemente antitéticas e irreconciliables, en aras de encontrar correspondencias y solucionar dilemas humanos de una elevada complejidad.

En otras palabras, aunque el modelo fue concebido como herramienta confiable para la demostración de divergencias e identificación de convergencias de este trabajo en particular - relacionadas con un área de estudio específico y en el marco de las disyuntivas que plantea el tránsito hacia un mundo más armónico - percibimos que el esquema bien pudiera transferirse a otros campos del saber científico. Esto es, ser útil como base para hacer propuestas de estudio y eslabonamientos de autores, disyuntivas teóricas o cognitivas equivalentes. Ojalá que el planteamiento pueda resultar de interés y utilidad a estudiosos de otras disciplinas, áreas de la ciencia y las humanidades. 
Por otra parte, ha resultado un instrumento innovador al estimar el contenido, peso y trascendencia de las contribuciones de Marx y Kierkegaard. Lo cual, ha permitido ahondar en sus disconformidades, pero también en sus proximidades, cayendo en cuenta que en pleno siglo XXI la mayoría de los seres humanos que habitamos en países y regiones del llamado mundo occidental no somos libres. Vivimos en sociedades aparentemente democráticas, pero atrapados en un sistema neo-totalitario o transpersonal de singular caracterización y manejo por estar vinculado a un fenómeno de concentración excesiva de la riqueza y del poder político en manos de una pequeñísima élite que ansía dirigir sin recato el destino de todos (incluso, convertirse en una cleptocracia sempiterna). Fenómeno que no tiene precedentes históricos. Por eso, el diálogo intercultural entre Marx y Kierkegaard en este trabajo ha sido una encomienda noble y necesaria, un cruce que apuesta por el equilibrio serio y la prudencia. Marx pugna por la igualdad en momentos en que se ha tocado fondo:

"El año pasado, el número de personas cuyas fortunas superan los mil millones alcanzó su máximo histórico, con un nuevo milmillonario cada dos días. En este momento hay 2043 milmillonarios (en dólares) en todo el mundo, de los que nueve de cada diez son hombres. La riqueza de estos milmillonarios también experimentó un enorme crecimiento, lo suficiente como para poder terminar con la extrema pobreza en el mundo hasta siete veces. El $82 \%$ del crecimiento de la riqueza mundial durante el último año fue a parar a manos del $1 \%$ más rico, mientras que la del $50 \%$ más pobre de la población mundial no aumentó lo más mínimo. Para poner fin a la actual crisis de desigualdad, es necesario que todos los trabajadores y trabajadoras del mundo disfruten de salarios y trabajos dignos. En todo el mundo, la economía del 1\% más rico se construye a expensas de trabajos mal pagados, a menudo ocupados por mujeres, que reciben salarios miserables sin que se respeten sus derechos fundamentales" (Informe OXFAM, enero de 2018: 9)

En contraste, Kierkegaard piensa que los individuos en la moderna "sociedad de masas" carecen de "pasión" e individualidad, que la destrucción de las comunidades locales y la creciente igualdad y uniformidad de la experiencia social humana están borrando las diferencias y que tales tendencias no sólo operan a escala regional y nacional, sino que son generalizadas (véase a Sean Sayers, 2011: 11).

Paradójicamente, Marx, aunque también describe la escala creciente de las relaciones sociales modernas, él las toma como efecto inherente a la expansión del capital. Una apreciación que es distinta porque deriva de su crítica al capitalismo. Marx no consideraba que todos los avances hacia la "sociedad de masas" señalados por el filósofo danés fuesen simples y únicamente negativos en sus efectos humanos (según Sayers, 2011:11),

"La globalización, la supresión de las diferencias locales, la igualación de la experiencia social, el crecimiento de la educación y la cultura de masas, incluso el nexo perverso del dinero omnipresente y la alienación provocada por el capitalismo ninguna de estas tendencias es puramente negativa o destructiva en su incidencia sobre la vida humana. A pesar de que estos desarrollos destruyen las comunidades locales, y fragmentan, "nivelan", homogeneizan o alienan a las personas, al mismo tiempo también crean relaciones y conexiones nuevas y más amplias entre ellas; y al hacerlo, abren oportunidades para el desarrollo y el cultivo de la persona, que antes sólo estaba disponible para una pequeña elite. Sin duda, esta variedad de actividades a menudo adopta formas mercantilizadas que limitan su valor humano. Sin embargo, cualquier explicación adecuada en torno al carácter de la sociedad moderna debe

XLinguae, Volume 12, Issue 3, June 2019, ISSN 1337-8384, eISSN 2453-711X 
tomar en cuenta ambos lados de la moneda, tanto el positivo como el negativo" (Sayers, 2011: 12).

Ahora bien, volviendo a Kierkegaard, como expresa el teólogo y filósofo norteamericano Owen Clark Thomas,

"Kierkegaard anhelaba rescatar al individuo que pensaba ilusamente que su espíritu estaba siendo perfeccionado gracias a su participación en la modernización de su país (Dinamarca). Idea que anidaba en el principio filosófico del individualismo desarrollado por Hobbes, Locke, John Stuart Mill y Adam Smith. Para Kierkegaard, este desarrollo nutría una "forma egoísta de subjetividad "[...] Por lo que, consideraba como socrática su obligación de despertar a su lector de tres ilusiones básicas: la ignorancia que pesaba sobre sí mismo, como un ser que se ama en forma egoísta y que desea lograr un identidad pública valiosa y reconocible; su auto convencimiento de que él era un Cristiano modelo; y su creencia en que Dinamarca era una nación cristiana" (2012: 74-75).

Como vemos, tanto Marx como Kierkegaard plantean disyuntivas político-sociales y morales muy poderosas y convergentes para el mundo occidental de nuestros días. No obstante que el existencialismo rechace la posibilidad de absolutos morales porque ello coloca principios universales por encima de las necesidades concretas de los individuos, ofrece en su lugar una vida libre de autoengaño. Una vida que posee hasta la finitud y la vulnerabilidad de la situación humana y, que acepta que sus acciones individuales siempre tienen un impacto en la vida de los demás (véase a Kevin Aho, 2014: 121). Como advierte el Informe OXFAM, enero 2018, actualmente, es difícil encontrar un líder político o un líder empresarial que no exprese públicamente su preocupación por la desigualdad.

Sin embargo, lo que cuenta son las acciones, no las palabras, y en esto casi todos los líderes se detienen. De hecho, muchos de ellos promueven activamente políticas que contribuyen al aumento de la desigualdad. Como expresa Napoleón Gómez, en los tiempos actuales la opulencia y el cinismo son cada vez más evidentes ante la mirada de los que poco o nada tienen. Los protegidos por el gobierno y los beneficiarios de toda esa desigualdad no quisieran que las naciones cambien, sino que el estado de cosas permanezca como está. Esos mismos ven a los promotores de cambio como los factores del retroceso y como los enemigos de la estabilidad y por eso tienen temor a las transformaciones, porque están cómodamente instalados en las mieles del imperio. Esos consideran a los partidarios de las innovaciones, no como sus adversarios políticos, sino como sus enemigos mortales a quienes quisieran destruir o eliminar. Por supuesto que eso se ha convertido en obsesivo y enfermizo para ellos, ya que carecen de todo sentido de responsabilidad social (2018: s/p).

Lo anterior, constituye un compromiso histórico y un dilema moral impostergable para Occidente. Máxime cuando hay Estados y culturas que se han sustraído a esa lógica, como pueden serlo China. Aunque el marxismo haya servido para introducir y hacer posible la modernidad en China de una manera un tanto forzada, como lo han sugerido recientemente Xilin, Yang Huilin y otros filósofos chinos (véase, David Lyle Jeffrey, 2011: 978), ha resultado ser menos eficaz para construir simultáneamente una crítica de la modernidad, dado que el marxismo se basa en presuposiciones materialistas en lugar de trascendentes. Sin embargo, ha sido el cristianismo el que paradójicamente ha venido a subsanar tal deficiencia, siendo quizás el puente o punto de encaje que vincule finalmente las reflexiones de Marx y Kierkegaard que hemos convocado en este ensayo. 
Como rememora Jeffrey, el eminente filósofo clásico chino Liu Xiaofeng, un marxista y un cristiano, a la vez, al mirar esta genealogía medio siglo después de la revolución de 1949, astutamente observó que "las traducciones de las obras de Marx y de obras clásicas occidentales (sobre filosofía y literatura), introdujeron en China una cultura del humanismo que contenía pensamientos cristianos " (2011: 978). En consecuencia,

"Entre el medio y este mensaje se ha producido una sinergia imprevista y creativa, ahora floreciente en muchas universidades chinas, donde aspectos del cristianismo y el marxismo se yuxtaponen inconsciente aunque dinámicamente, generando allí por primera vez, tal vez, las condiciones para el surgimiento de algunas de las características sólo encontradas en la historia católica y cristiana de otros lugares anteriores a la Universidad occidental. Condiciones varias que uno espera que al menos Alasdair MacIntyre apreciara, si no totalmente aprobara, el movimiento del marxismo idealista, a través de sus decepciones, a una búsqueda renovada de la verdad y lo bueno en el mundo académico chino en alguna medida refleja su propia desarrollo intelectual personal, a partir de un idealismo marxista anterior basado en principios a su papel maduro como uno de los mejores portavoces contemporáneos para un concepción genuinamente católica de la universidad. Pero cuál es su argumento y resumen conciso de la relación entre la teología y la vida intelectual de la universidad dejar claro, es que ninguna universidad puede permanecer creíblemente abierta a una relación correcta entre la vida de la mente y la búsqueda del bien común que no mantiene y avanzar la prominencia de teología y reflexión teológica entre las disciplinas" (Jeffrey, 2011: 978).

\section{Bibliographic references}

AHO, K. 2014. Existentialism: An Introduction, Cambridge: Polity Press. 193 p. ISBN 9780745651422

BRANDEIS L. 2019. Louis D. Brandeis Legacy Fund for Social Justice, Available online: https://www.brandeis.edu/legacyfund/bio.html

DIP, P. C. 2011. Kierkegaard y Marx en la filosofía de la historia de Karl Lowith en Memoria Académica:. VIII Jornadas de Investigación en Filosofía, 27 al 29 de noviembre de 2011. La Plata. Espacios de diversión, pp. 1-15. Available online: http://jornadasfilo.fahce.unlp.edu.ar/viii-jornadas-2011. ISSN: N/D.

ESTULIN, D. 2013. El club de los inmortales, Ediciones B, S.A., Barcelona, 277 p. ISBN: 9788466653084

ESTULIN, D. 2015. Fuera de control, Editorial Planeta, Barcelona, 334 p. ISBN 10: 6070735994 ISBN 13: 9786070735998

GÓMEZ URRUTIA, N. 2018. La decadencia moral de un gobierno, Periódico La Jornada, Jueves 5 de abril de 2018 Available online: http://www.jornada.unam.mx/2018/04/05/opinion/018a1pol.

JEFFREY, D. L. 2011. Marxist and Christian: MacIntyre and the Postmodern University, en Nova et Vetera (English Edition), Fall 2011, Vol. 9, n.4, pp. 967-989. ISSN 1542-7315

KIERKEGAARD S. 2009a. Ejercitación del cristianismo, (tr. Demetrio Gutiérrez Rivero), Editorial Trotta, Madrid, c1850, 256 p. ISBN: 9788498790559

KIERKEGAARD S. 2009b. Concluding Unscientific Postscript, (tr. Alastair Hannay), Cambridge University Press, Cambridge, UK, 536 p. ISBN-10: 0521709105; ISBN13: 9780521709101

KIERKEGAARD S. 1999. Migajas filosóficas o un poco de filosofía. (tr. Rafael Larraneta), Editorial Trotta, Valladolid, España, 1999, 111 pp. ISBN: 9788481644418. KIERKEGAARD S. 1985. Mi punto de vista sobre mi labor como escritor, (tr. José Miguel Velloso), Sarpe, Madrid, c1847, 203 p. ISBN 10: 8472917452; ISBN 13: 9788472917453 
KIERKEGAARD S. 2012. La época presente. (tr. Manfred Swensson), Editorial Trotta, Madrid, 93 pp. ISBN: 978-84-9879-315-4

KIERKEGAARD S. 2008. La enfermedad mortal. (tr. Demetrio Gutiérrez Rivero), Editorial Trotta, Madrid. ISBN 978-84-9879-055-9

MARX, K. 1981. El capital, Crítica de la economía política. El proceso global de la producción capitalista en su conjunto, Tomo III, Vol. 8, Siglo XXI Editores, México D.F., pp.791-1314. ISBN: 9789682309168.

OWEN. C. T. 2012. Kierkegaard's Attack upon Christendom, and the Episcopal Church. En Anglican Theological Review, Winter 2012, Vol. 94, n.1, pp.59-78. ISSN: N/D.

PARRY C. J. 2007. Preámbulo del DCDC Global Strategic Programme, 2007-2037.

PAVLIKOVA, M. 2018. The Power of Modern Technologies in the Fictional of Don Delillo. En Komunikacie, Communications, Vol. 20, n. 2, pp..57-60. ISSN 1335-4205.

RECASENS SICHES, L. 1965. Tratado general de Filosofía del Derecho. Editorial Porrúa, México, D.F. 717 p. ISBN: 9789700764801

ROBINSON, W. I. 2013. Una Teoría sobre el capitalismo global. Producción, clase y Estado en un mundo transnacional. (tr. Víctor Acuña Soto y Myrna Alonzo Calles). Siglo XXI Editores, México, D.F., 246p. ISBN: 9786070305177.

S/A. 2007. DCDC Global Strategic Trends Programme 2007-2036, (Development, Concepts and Doctrine Centre (DCDC), a Directorate General within the UK's Ministry of Defense (MOD), Third edition, London, January 2007, 91p. Available online:

http://www.mod.uk/DefenceInternet/AboutDefence/Organisation/AgenciesOrganisati ons/DCDC/ ISBN N/D.

S/A. OECD Employment Outlook 2012. Summary in Spanish: Available online: https://www.oecd-ilibrary.org/docserver/empl_outlook-2012-sum-

es.pdf? expires $=1549385905 \& \mathrm{id}=$ id\&accname $=$ guest $\&$ checksum $=436$ F5395346FE7D 6411F8B2E82DEDF6D.

S/A. 2018. Premiar el trabajo, no la riqueza, Informe de OXFAM, enero de 2018, publicado por Oxfam GB para Oxfam Internacional, London, 92 p. ISBN 978-178748-136-7.

S/A. 2014. Gobernar para las élites. Secuestro democrático y desigualdad económica, Informe de OXFAM, n. 178, 20 de enero, 2014, publicado por Oxfam GB para Oxfam Internacional, London, 34 p. ISBN: N/D.

SAYERS, S. 2011. The Concept of Alienation: Hegelian Themes in Modern Social Thought. In Marx and Alienation, Palgrave Macmillan, London, pp. 11 a 13. ISBN: 978-0-230-27654-3.

Words: 9109

Characters: 59486 (33,05 standard pages)

Prof. Investigador Titular 'C' Humberto Ortega-Villaseñor, PhD.

Departamento de Estudios Literarios

Doctorado en Humanidades

Universidad de Guadalajara

Parres Arias 150, Esq. Periférico Norte,

45100 Núcleo Los Belenes

Zapopan, Jalisco

México

Edificio A, primer nivel

huorvi@gmail.com 